\title{
Penyajian Teh oleh Teishu dalam Ritual Sadoo: Potret Representasi Karakter Bangsa Jepang
}

\author{
Reny Wiyatasari \\ Program Studi Bahasa dan Kebudayaan Jepang, Fakultas Ilmu Budaya \\ Universitas Diponegoro Semarang - Indonesia \\ Email : reny.wiyatasari@gmail.com
}

\begin{abstract}
SADOO -- is one of the culture of the Japanese that still awake its sustainability in the midst of globalization and modernization. Sadoo in Japan is influenced by Zen Buddhism. Therefore sadoo is believed to be one of the richest cultures of meaning and value of life, such as social values, discipline, beauty, and etiquette. It is illustrated by the strict rules of conduct carried out and observed by the teishu during the invited guest ritual and o-kyaku. In this article, the author will discuss the presentation of tea by teishu in a sadoo ritual; how a teishu presents tea, what matters and what to watch for and do so that one can perform sadoo rituals, actions, movements and attitudes of a teishu during the sadoo ritual. These things are believed to be a reperesentation of the character of the Japanese known for its discipline, hardworking, thorough, diligent, well organized, manners, and ethics
\end{abstract}

Keywords: sadoo, teishu, o-kyaku, Zen Buddhism

\section{Pendahuluan}

Jepang dikenal sebagai salah satu bangsa di dunia yang unggul di bidang tehnologi dan ekonomi, dan ini tidak lain karena bangsa Jepang sendiri adalah bangsa selalu menjaga kedisiplinan, etos kerja yang kuat, serta berkomitmen tinggi terhadap pekerjaan yang dilakukannya. Meskipun unggul dibanding negara-negara di Asia lainnya, Jepang ternyata adalah negara yang kaya akan budaya tradisional dan sampai sekarang budaya tersebut masih tetap dijaga dan dihormati eksistensinya. Budaya tradisional, di antaranya ikebana, origami, sadoo, budaya makanan, budaya pakaian, dan sebagainya bahkan dikenal sampai berbagai penjuru dunia. Budaya merepresentasikan sebagian besar cara pikir, konsep dan kebiasaan yang dimiliki oleh suatu bangsa, sehingga bila membahas karateristik, khususnya karakter bangsa Jepang, maka tidak salah bila mengkaitkannya dengan kebudayaan yang mereka miliki.

Dalam artikel ini, penulis tertarik untuk mengangkat tulisan tentang tradisi minum teh atau dikenal juga sebagai upacara minum teh yang dalam bahasa Jepang dikenal dengan istilah shadoo atau chadoo atau chanoyu. Sadoo diyakini menjadi salah satu budaya yang sarat akan makna dan nilai hidup yang mendalam, seperti nilai- nilai sosial, kedisiplinan, keindahan, serta tata krama/etika, dan itu tergambar melalui aturan perilaku yang ketat yang dijalankan dan dipatuhi oleh teishu 'tuan rumah' dan o-kyaku 'tamu' yang diundang selama ritual dilakukan. Di samping itu, tata cara dari persiapan hingga penyajian selama melakukan ritual tradisional ini dilakukan dengan 
menggunakan gerakan dan sikap yang diatur sedemikian rupa yang mengandung makna serta nilai-nilai filosofi yang tinggi.

Tradisi sadoo ini berumur ratusan tahun dan meliputi kegiatan membuat, menyajikan dan menikmati minuman teh dengan cara khusus yang formal. Dikenal pertama kali pada abad ke-9, dan pada saat masuk ke Jepang mendapat pengaruh dari aliran Budhisme Zen. Biksu dan biarawan Budha Zen, yang telah minum teh untuk keperluan medis sejak abad ke-13, memiliki kebiasaan minum teh secara kolektif sebagai bagian dari kode perilaku pertapa (shingi) yang diperkenalkan dari China. Kebiasaan minum teh tidak hanya bermanfaat untuk pengobatan atau kesehatan, namun juga menyenangkan, sehingga pada pertengahan abad ke-16 atau pada masa Edo (1603-1898) kebiasaan yang awalnya hanya dilakukan oleh kaum bangsawan dan kelas samurai mulai banyak dikenal oleh masyarakat biasa dan mengalami perkembangannya yang cukup signifikan.

Sepanjang sejarahnya, orang Jepang memiliki pandangan terhadap dunianya dengan menerjemahkan konsep-konsep abstrak dalam kebudayaannya menjadi penerapan-penerapan yang dapat bermanfaat (Lawanda, 2009 : 5). Upacara minum teh, seni merangkai bunga (ikebana), irisan-irisan kecil makanan dari laut semuanya menunjukkan betapa teliti mereka dalam mengatur kehidupan mereka (Budi Dharma dalam Soepardjo \& Wawan, 1999) Karena itu, penulis tertarik untuk membahas lebih dalam tentang penyajian teh oleh teishu dalam ritual sadoo. Melalui pengetahuan di antaranya tentang bagaimana seorang tuan rumah (seorang teishu) dalam menyajikan teh, hal penting dan apa saja yang harus diperhatikan dan dilakukan hingga seorang bisa melakukan ritual sadoo, maka bisa ditarik simpulan berkaitan dengan ritual sadoo yang dilakukan oleh teishu yang merepresentasikan karakter bangsa Jepang. Oleh karena itu, fokus dari artikel ini adalah membahas tentang bagaimana seseorang teishu dalam ritual sadoo dan bagaimana seseorang untuk bisa menjadi teishu, serta tindakan/gerakan dan sikap teishu saat melakukan ritual sado, karena melalui halhal tersebut mempresentasikan karakter bangsa Jepang.

\section{Sejarah Sadoo}

Sasaki (1995) dan Ueno (2005) dalam tulisannya menjelaskan secara singkat sejarah sadoo (chadoo/chanoyu) atau tea ceremony yang apabila diringkas adalah sebagai berikut. Tradisi sadoo di Jepang memiliki sejarah yang panjang dan merupakan kebudayaan yang berasal dari China dan dibawa ke Jepang oleh biksu agama Budha, sehingga ritual tradisional ini banyak mendapat pengaruh dari ajaran agama Budha aliran Zen. Kijebudayaan tradisional ini disempurnakan oleh Zen no Rikyu sekitar abad ke 16 (1522-1591), yaitu selama masa perang sipil (sengokujidai). Pada masa perang sipil ini, hadirnya kebiasaan minum teh justru menjadi sesuatu yang diperlukan karena menikmati teh dengan tenang bagi para prajurit yang hampir setiap harinya hidup di medan pertempuran menjadi saat 
bagi mereka untuk menenangkan pikiran. Sejak saat itu, sadoo menjadi salah satu contoh etika bangsa Jepang. Sadoo yang merupakan ritual tradisional mengandung ajaran, di antaranya tentang displin mental untuk mengejar atau mendapatkan wabi, yaitu keadaan pikiran yang tenang dan puas, dengan kesederhanaan yang mendalam, di samping juga pada saat yang sama melakukan ritual tradisional ini menjadi suatu pertunjukan yang mana bentuk dan rahmat adalah yang terpenting. Namun demikian, disiplin adalah tujuan bagi setiap orang yang mempraktekkan upacara minum teh, dan bukan bertujuan untuk penampilan diri. Semangat wabi sendiri dicontohkan salah satunya melalui bentuk ruang untuk upacara minum teh atau chashitsu yang biasanya memiliki luas sebesar tiga meter persegi atau 4,5 luas tatami (tikar tenunan dari jerami) serta didekorasi dengan sangat sederhana.

Upacara minum teh telah membentuk satu sistem budaya (bunkataikei) dengan menyerap segala sesuatu, setiap aspek budaya (Jepang). Ada tiga sekolah utama upacara minum teh yang disebut Sansenke. Nama ini berasal dari Sen no Rikyu yang merupakan kakek buyut dari para pendiri dari tiga sekolah utama. Disebut sebagai sekolah utama karena garis darah menghubungkan mereka ke grand master upacara minum teh Sen no Rikyu. Ketiga sekolah keluarga Sen menerapkan "Sen" dalam nama sekolah mereka, yaitu urasenke, omotesenke, dan musanookojisenke. Alat-alat yang digunakan selama melakukan ritual tradisi ini, di antaranya : hishaku (centong air), okama (gentong air), chawan (mangkuk teh), chasaku (sendok teh), natsume (wadah bubuk teh), chasen (pengaduk teh), matcha (bubuk teh hijau), dan sebagainya. Penggunaan alat-alat tersebut juga diatur sedemikian rupa dengan urutan yang tepat dan gerakan yang sudah ditentukan. Tidak hanya teishu, bagi o-kyaku diundang dalam ritual sadoo, berbagai aturan, seperti cara berjalan, cara memegang sumpit dan chawan, cara mengambil okashi atau camilan, cara duduk, cara minum dan sebagainya menjadi hal-hal yang harus diperhatikan dan dipelajari dengan baik.

\section{Teishu dalam Ritual Sadoo}

Mempersiapkan teh dalam upacara ini berarti menuangkan semua perhatian ke dalam suatu gerakan yang telah diatur sedemikian rupa. Seluruh prosesnya bukan tentang minum teh, tetapi tentang estetika menyiapkan semangkuk teh dari hati seseorang (omotenashinokokoro). Gerakan dan sikap teishu selama melakukan ritual membuat dan menyajikan teh selalu dilakukan dengan memikirkan atau mempertimbangkan siapa tamu yang hadir, misalnya dalam penempatan peralatan teh, seorang teishu harus mempertimbangkan jenis/bentuk dan posisinya dari sudut pandang tamu, terutama tamu kehormatan yang disebut shokyaku.

Persiapan ritual minum teh sangat sederhana, kesederhanaan adalah salah satu dasar untuk menyiapkan semangkuk teh hijau untuk para tamu. Namun, 
setiap langkah persiapan memiliki gerakan tetap, dan peralatan harus ditempatkan di lokasi yang ditentukan sebelumnya di tikar tatami. Minum teh dan menyajikan teh dipenuhi oleh kedalaman spiritual dan keheningan yang mendalam dan ketenangan. Gaya persiapan bervariasi sesuai dengan musim atau tingkat formalitas pertemuan.

Dalam ritual sadoo terdapat begitu banyak istilah yang berkaitan dengan hiasan/ornamen yang terdapat dalam chashitsu atau alata-alat yang digunakan selama ritual, gerakan yang dilakukan sesuai aturan serta ekspresi-ekspresi yang diucapkan baik oleh teishu maupun o-kyaku. Disebutkan terdapat banyak sekali istilah gerakan tubuh yang digunakan oleh tuan rumah saat melakukan ritual upacara minum teh dihadapan tamu-tamunya, namun setidaknya ada 4 istilah utama untuk gerakan tubuh, yaitu temae, shosa, tachiifurumae, dan izumai. Secara umum temae (手前) adalah salah satu istilah umum yang sering digunakan pada ritual sadoo dan menunjuk pada tindakan, cara/metode, dan etika teishu dalam membuat teh (mis : menyalakan tungku arang, menuang, dan mengaduk teh). Temae yang merupakan aturan gerakan tubuh untuk membuat teh menjadi dasar semua unsur upacara minum teh dan menjadi istilah teknis yang digunakan secara eksklusif dalam upacara minum teh. Semua latihan dalam temae adalah tentang disiplin gerakan tubuh dan ketepatan sikap dan gerakan saat menggunakan peralatan. Cara berkomunikasi dan gerakan tangan, kaki, atau postur tubuh secara keseluruhan diatur prosedur yang terdapat pada temae, dan semua itu didasarkan pada lima kebajikan dalam ajaran Konghucu yang meliputi : kesetiaan, kebenaran, kesopanan, kebijaksanaan dan kepercayaan Etsuko (2004 : 26-39).

Temae secara alami mengarahkan pada praktik moral yang harus disesuaikan oleh setiap manusia. Hal yang dominan pada temae adalah pada penekanan tidak terputusnya hubungan antara gerakan tubuh dan pikiran. Oleh karena itu, temae sangat penting dalam segala bentuk upacara minum teh dan telah menjadi bagian integral dari upacara minum teh sepanjang sejarah. Membuka pintu geser, membungkuk, mengaduk bubuk teh dengan air panas - semua tindakan ini bukan sekadar tindakan tangan atau kepala tapi juga tindakan punggung yang diluruskan dengan benar, siku terjepit, atau jari-jari disatukan rapi.

Temae dipelajari dan dipraktekan oleh seseorang melalui pelatihan yang disebut keiko. Keiko adalah acara pertama dan terdepan untuk mendisiplinkan gerakan tubuh seseorang. Keiko dianggap sebagai pelatihan parsial dan persiapan saat seseorang menampilkan ritual sadoo dalam chakai (pertemuan formal besar) dan chaji (pertemuan formal kecil).

Gerakan utama yang kedua adalah shosa yang juga mengacu pada gerakan tubuh yang diatur oleh aturan, tapi tidak seperti temae, shosa tidak hanya mengacu pada gerakan pembuatan teh, namun juga gerakan minum teh dan gerakan lainnya di ruang teh. Selanjutnya, gerakan utama yang ketiga adalah tachi-ifurumai, yang secara harfiah berarti perilaku berdiri dan duduk. Hampir identik 
dengan shosa, referensinya diperluas ke keheningan (duduk) serta gerakan. Tachii-furumai juga mengacu pada gerakan dan keheningan yang tidak selalu berhubungan dengan membuat atau minum teh, seperti berdiri, duduk, berjalan, atau membuka pintu geser.

Terakhir adalah I-zumai yang mengacu pada keseluruhan postur duduk, dan karena itu memiliki lebih banyak konotasi keheningan daripada gerakan. Oleh karena itu, selama ritual tradisional ini berlangsung, biasanya baik teishu maupun o-kyaku lebih banyak berdiam. Di antara para tamu yang hadir pun hampir tidak ada percakapan. Mereka bersantai sambil menikmati suasana tenang yang tercipta dari suara air, api, aroma dupa dan teh, serta situasi keindahan dan kesederhanaan yang tercipta dari chashitsu dan dekorasi di dalamnya. Kalaupun ada percakapan, biasanya hanya percakapan formal antara teishu dengan shokyaku (tamu kehormatan) tentang teh, manisan, dan peralatan yang digunakan.

Dalam ritual sadoo, semakin tinggi tingkat/level kemampuan teishu, maka semakin kompleks cara, gerakan, dan sikap selama dan pada saat pembuatan teh serta semakin bermacam jenis, bentuk, dan ukuran peralatan yang digunakan. Misalnya, teishu harus meletakkan satu tangan di lantai saat membuka pintu geser dan meletakkan kedua tangan di lantai setelah menawarkan peralatan kepada para tamu agar terlihat lebih dekat dan sekaligus untuk menunjukkan kesopanan yang tinggi. Disiplin jasmani seperti itu mengarah pada kontrol mental, karena praktik berulang yang dibutuhkannya tidak dapat dilakukan tanpa sikap mental yang dapat diungkapkan sebagai refleksi diri, kerendahan hati, ketekunan atau disiplin diri.

\section{Representasi Karakter Bangsa Jepang melalui Ritual Sadoo oleh Teishu}

Etsuko $(2004,38)$ dalam bukunya menuliskan bahwa upacara minum teh adalah disiplin tubuh (bodily discipline). Kata "disiplin', menurut Etsuko, berarti pengendalian tubuh. Dengan kata lain, ada hubungan antara gerak tubuh dengan pikiran atau kontrol tubuh mempengaruhi kontrol pikiran (mengendalikan gerakan tubuh untuk mengendalikan pikiran). Tidak hanya itu saja, seorang teishu membutuhkan sikap tubuh yang tepat agar dapat melakukan gerakan yang benar juga selama pembuatan dan penyajian teh. Untuk dapat melakukan gerakan dan sikap tubuh yang tepat dan benar, seorang teishu memerlukan pelatihan dalam waktu yang tidak sebentar, dan pelatihan sadoo bisa dinyatakan merupakan pelatihan sepanjang hayat. Karena itu, semakin lama waktu pelatihan, semakin tinggi level seorang teishu, semakin komplek peralatan digunakan dibanding tingkat lebih rendah. Tidak hanya cara membuat teh tapi juga sikap terhadap sekelilingnya juga harus berubah sesuai level masing-masing. Misalnya, seorang teishu harus meletakkan satu tangan di lantai saat membuka pintu geser, dan meletakkan kedua tangan di lantai setelah menawarkan peralatan kepada para tamu agar terlihat lebih dekat, serta untuk menunjukkan tingkat kesopanan yang 
semakin tinggi. Bisa dikatakan bahwa semakin ahli seorang teishu menyajikan teh, maka semakin tinggi dan jelas falsafah dan pandangan hidup yang dimilikinya. Gerakan dan sikap seorang teishu selama ritual sadoo bisa dinyatakan sebagai reperesentasi karakter bangsa Jepang yang dikenal sebagai bangsa yang disiplin, kerja keras, tekun, teliti, well organized, menjunjung tata krama dan etika. Berikut akan diuraikan masing-masing karakter yang dimiliki oleh bangsa Jepang tersebut.

\subsection{Disiplin}

Selama ini kita mengenal nilai disiplin sebagai salah satu karakter bangsa Jepang. Nilai disiplin bisa deskripsikan sebagai tindakan yang menunjukkan perilaku tertib dan patuh pada berbagai ketentuan dan peraturan. Kedisiplinan bangsa Jepang ini bisa dilihat di antaranya dari budaya memilah sampah, budaya antri, dan kepatuhan dalam berlalu lintas. Sampah dikeluakan dan diangkut sesuai dengan aturan dan semua masyarakat mematuhinya dengan baik.

Murni dalam bukunya menuliskan bahwa: kedisiplinan orang Jepang bukanlah penampakan dari genetik tetapi lahir dari pembinaan dan pendidikan sejak kecil yang kemudian melahirkan pemahaman, kesadaran, dan kepekaan terhadap berbagai permasalahan yang muncul di tengah masyarakat, kekurangyamanan, ketidakpuasan terhadap pelanggaran nilai-nilai bersama, dan keinginan untuk menjadi lebih baik (Murni, 2018: 113). Dari sini bisa diketahui bahwa untuk menjadi seperti sekarang ini masyarakat Jepang mendidik dirinya dengan keras sejak kecil dan didikan tersebut tidak hanya didapat dari pendidikan formal, namun keluarga dan lingkungan juga mendukung terbentuknya karakter tersebut, pendidikan tersebut berhasil membentuk masyarakat Jepang yang disiplin seperti sekarang ini.

Demikian juga dalam ritual sadoo, karakter disiplin bangsa Jepang ini dipresentasikan melalui bagaimana seseorang yang ingin menjadi teishu berlatih agar dapat menyajikan teh dengan benar dihadapan para tamu, dan meskipun sudah mampu, seorang teishu tetap disiplin dalam berlatih dengan tujuan agar semakin tinggi levelnya dan semakin tinggi filosofi hidupnya.. Kedisiplinan adalah suatu proses, dan proses dalam ritual sadoo yang secara berulang dilakukan secara tidak langsung menjadi cara untuk melatih kedisiplinan diri. Nilai kedisiplinan yang dimiliki oleh seorang teishu ini diyakini ada kaitannya dengan sejarah sadoo yang mendapat banyak pengaruh dari ajaran Budha Zen yang memiliki ciri utama meditasi dan kedisiplinan. Dalam ajaran Zen : seseorang bisa mencapai pencerahan melalui meditasi, kedisiplinan, dan menjaga harmoni dengan sesama manusia. Ajaran inilah yang sepertinya merupakan konsep penting yang dianut dan dijalankan oleh masyarakat Jepang dalam kehidupan mereka.

\subsection{Kerja Keras dan Tekun}


Merupakan salah satu nilai yang ditunjukkan lewat perilaku berupaya atau berusaha sungguh-sungguh dalam mengatasi berbagai hambatan yang dihadapi dalam pekerjaan atau tugas dan menyelesaikan pekerjaan atau tugas dengan sebaik-baiknya. Sebagai negara dengan luas wilayah sedikit lebih besar daripada pulau Jawa, Jepang dikenal sebagai salah satu negara yang penduduknya masuk dalam kategori pekerja keras.

Dalam sadoo, karakter ini direpresentasikan melalui kerja keras dan ketekunan seorang teishu untuk mempelajari dan melatih diri agar dapat menyajikan teh dengan cara yang benar, dan demi hal tersebut mereka memerlukan jangka waktu yang tidak sebentar, bahkan seorang teishu dinyatakan perlu melakukan pelatihan sepanjang hayat untuk dapat meningkatkan level dalam menyajikan teh. Karena itu, meskipun sudah dinyatakan mampu dan mendapat pengakuan untuk menyajikan teh, seorang teishu terus meningkatkan dan menyempurnakan teknik mereka. Biasanya semakin tinggi level seorang teishu, semakin tinggi filosofi hidup yang dimilikinya. Etsuko (57) menuliskan bahwa tidak jarang teishu yang ingin menjadi tea master mengambil beberapa dekade untuk menyelesaikan semua langkah latihan. Lebih lanjut Etsuko juga menyatakan bahwa disiplin jasmani berupa pelatihan tingkat tinggi yang merupakan akumulasi kombinasi gerakan tubuh yang berbeda dan kompleks mengarah pada kontrol mental. Karena dibutuhkan praktik berulang, maka tidak dapat dilakukan tanpa sikap mental berupa 'refleksi diri', 'kerendahan hati', 'ketekunan' atau 'disiplin diri'.

\subsection{Teliti dan Well organized.}

Orang Jepang dikenal sangat teliti dan well organized dalam bekerja. Ketelitian tersebut salah satunya ditunjukkan dari Salah satunya ditunjukkan oleh kebiasaan mereka memperhatikan dengan baik urutan atau langkah-langkah saat akan mengerjakan sesuatu. Membaca dengan teliti buku petunjuk dan mengerjakan sesuai petunjuk yang ada. Bila ada kerusakan, mereka. Ada tiga peribahasa untuk menggambarkan tentang orang Jepang berkaitan dengan konsep mereka dalam bekerja, yaitu : Shinken da to chie ga deru 'orang yang serius bekerja maka kepandaian dan kebijaksanaan akan muncul dari dalam dirinya, chuuto hanpa wa kuchi ga deru 'orang yang mengerjakan sesuatu setengah-setengah, maka dia akan banyak mengeluh', dan iikagen da to iiwakebakari 'orang yang tidak memiliki ilmu, dan cenderung banyak omong, selalu mencari-cari alasan yang tidak masuk akal' Murni $(2018: 125)$.

Dalam ritual sadoo, karakter di atas dipresentasikan oleh teishu yang melakukan ritual secara teliti dari persiapan berupa merebus air, menyiapkan bubuk teh hijau, menyajikannya kepada tamu dan meminumnya sendiri. Ketelitian sangat penting supaya teh yang dihasilkan adalah teh yang baik yang 
dipenuhi dengan busa halus dan saat habis diminum hanya akan meninggalkan busa dan bukan bubuk teh. Teh juga harus disajikan dalam keadaan panas, harus bersih dan tidak boleh ada kotoran sedikitpun. Sedangkan karakter well organized atau kerapian/keteraturan bangsa Jepang bisa digambarkan dari sikap gerakan teishu saat membersihkan semua peralatan yang akan digunakan dihadapan para tamu, meletakkan semua peralatan yan sudah dibersihkan di tempatnya, membuat teh dan menyajikan teh sesuai posisi tamu yang hadir.

\subsection{Tata Krama dan Etika}

Bangsa Jepang dikenal sebagai bangsa yang selalu menjaga tata krama dan etika. Ojigi atau membungkukkan badan adalah salah satu budaya khas masyarakat Jepang yang menggambarkan sikap bangsa Jepang yang sangat menjunjung kesopanan dan penghormatan kepada orang lain. Dalam berbagai kesempatan, saat seorang pejabat menyambut tamu, atau saat seorang pejabat meminta maaf di hadapan publik karena telah berbuat kesalahan, ojigi menjadi gerakan yang pasti akan dilakukan oleh pejabat tersebut dengan tipe yang berbeda antara membungkuk untuk menyambu tamu dan membungkuk untuk meminta maaf. Di samping itu, kata-kata, seperti sumimasen 'maaf' yang diucapkan di antaranya pada saat seseorang merasa telah merepotkan atau menggangu orang lain juga menggambarkan kesopanan yang menjadi karateristik bangsa Jepang. Melalui ritual sadoo oleh teishu pun dapat diketahui bagaimana karakter bangsa Jepang sebagai bangsa yang menjaga tata krama dan etika. Telah dinyatakan di atas bahwa ritual sadoo bukan semata-mata hanya ritual minum teh, namun lebih dari itu merupakan tentang estetika menyiapkan semangkuk teh dari hati seseorang (omotenashinokokoro). Tata krama dan etika harus dipahami dengan dan benar-benar ditaati oleh seorang teishu dalam menjamu tamu yang hadir, di antaranya dalam membuat dan menyajikan teh selalu dilakukan dengan memikirkan atau mempertimbangkan siapa tamu yang hadir, misalnya dalam penempatan peralatan teh, seorang teish $u$ harus mempertimbangkan jenis/bentuk dan posisinya dari sudut pandang tamu, terutama tamu kehormatan yang disebut shokyaku. Di samping itu, saat temae dipelajari dan dipraktekan oleh seseorang melalui pelatihan, salah satunya yaitu tachi-i-furumai yang secara harfiah berarti perilaku berdiri dan duduk yang mengacu pada gerakan dan keheningan, seperti berdiri, duduk, berjalan, atau membuka pintu geser. Semua tindakan ini bukan sekadar tindakan tangan atau kepala tapi juga tindakan punggung yang diluruskan dengan benar, siku terjepit, atau jari-jari disatukan rapi. Semua gerakan tersebut dilakukan berdasarkan etika dan ditampilkan dengan sikap sopan santun yang tinggi 


\section{Simpulan}

Menjadi seorang teishu membutuhkan pembelajaran dan pelatihan sepanjang hayat. Penyajian teh dari persiapan hingga penyajian dilakukan dengan aturan yang ketat, baik dari sikap, gerakan, dan postur tubuh. Penggunaan, cara membersihkan dan peletakan peralatan juga dilakukan secara urut. Demikian juga saat teh disajikan kepada para tamu. Hal-hal tersebut Hal-hal tersebut diyakini merupakan reperesentasi karakter bangsa Jepang yang dikenal dengan kedisiplinannya, pekerja keras, ketelitiannya, tekun, well organized, dan menjaga sopan santun serta tata krama

\section{Daftar Pustaka}

Tim Cross. 2009. The Ideologies of Japanese Tea. Subjectivity, Transience and National Identity. Global Oriental LTD

Kato, Etsuko. 2004. The Tea Ceremony and Woman's Empowerment in Modern Japan. RoutledgeCurzon. Taylor \& Francis Group. London and New York

Kouichi, Ueno. 2005. 日本絵とき事典 1. Illustrated. A Look Into Japan. JTB パブリッツグ. Tokyo

Lawanda, Ike Iswary. 2009. Matsuri dan Kebudayaan Korporasi Jepang. ILUNI Kajian Wilayah Jepang Press. Jakarta

Nakane, Chie. 1984. Japanese Society. Penguins Books.

Ramli, Murni. 2018. Menjadi Orang Berkarakter dan Berbudaya di Jepang. Manggar Media. Yogyakarta.

Sasaki, Mizue. 1995. View of Today's Japan. ALC. Tokyo

Soepardjo, Djodjok \& Wawan Setiawan. 1999. Budaya Jepang Masa Kini (Kumpulan Arikel). CV. Bintang. Suarabaya

Sugimoto, Yoshio. 2002. An Introduction to Japanese Society. Cambride University Press.

Varley, Paul. Japanese Culture. 2000. University of Hawai'i Press. Honolulu. 